\title{
Impact of interactive aerosol on the African Easterly Jet in the NASA GEOS-5 global forecasting system.
}

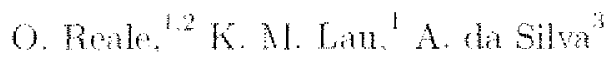

O. Reale. Laboratory for Atmospheres, Code 613, NASA Goddard Space Flight Center. Greenbelt, MD 20771, USA. (Oreste Renle-lonasigov)

NASA Goddard Space Flight Center.

Laboratory for Amospheres, Greenbelt,

Maryland, USA.

2University of Maryland, Batinore

Comnty, Baltinore, Maryand. USA.

3NASA Goddand Space Flight Center.

Global Modeling and Assimilation Offec.

Maryland. USA.

$D R A F T$

July $16,2010,4: 41 \mathrm{pm}$

DRA F T 
$x-2$

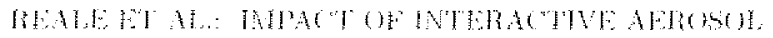

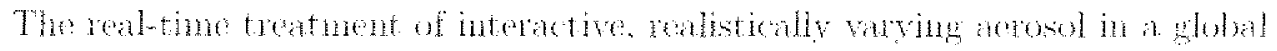

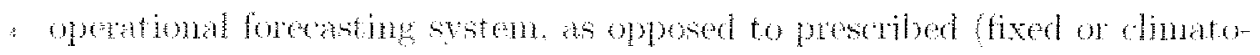

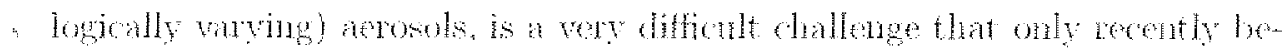
gins to be adtressed. Experiment ments from a recent rersion of the NASA

- GEOS-5 foreating system. inclusive of interactive nerosol treatment, are

" presented in this work. Fon sets of 30 -day forechots are initialized from

" a high qualty set of analyses previonsly produced and docmented, to cover

"the period from 15 Angust to 16 Septenber 2006 , whith comesponds to the

"NASA African Monson Multidsciphary Analysis (NAMMA) observing cam-

"2 paign. The four foreast sets are at two diferent horizontal resolutions and

: with and withont interactive acrosol treatment. The net impact of aerosol,

in at times in which there is a strong dnst ontbreak, is at temperature increase

is at the dust level, and decrease in the near-surface levels, in complete agree

: ment with previons observational and modeling studies. Moreover, forecasts

" in which interactive aerosols are included depict an Afrean Easterly let at

: slightly higher elevation, and slightly displaced northward, with respect to

s the forecasts in which atrosos are not included. The shift in the AFJ po-

wa sition goes in the direction of observations and agrees with previons results.

DRAFT July 16, 2010, 4:41pm DR AF T 


\section{Introduction}

$\therefore$ The role of the Salaman Air Laver (SAL) has been sugrested to be relewant to weather

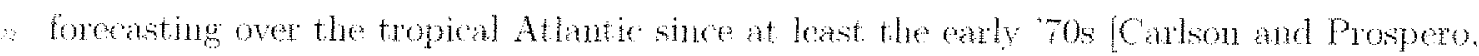

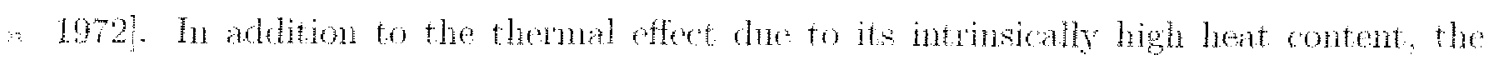
s role of dist in terms of dired malive efect has ben intensely investigated for several " tecads (e.g. Carlson and Benjamin, [1980). Suface and space-based measurements of * amosphenc optical thickness (AOT) go back to the late $70 \mathrm{~s}$ (e.g. Carlson and Wending. * 1977) but the possibilities of merging motem-eta satellitess with data such as the ones 3* coming from Moderate Resolution Imaing Spectrondioneter (MODIS) or Clond-Aerosol

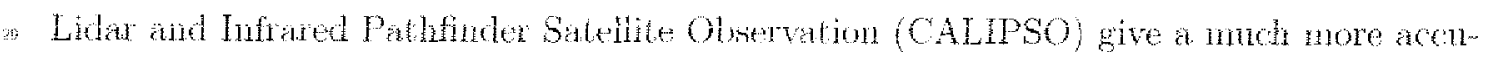
: rate understanding of aerosols optical properties (e.g. TRemer et al. 2008; Omar of al. $: 2009]$

3. Among the various effects of dust over the tropical atmosphere, Dumion and Velden 33 [2003] suggested a role of dust unfavorable to tropical cyclogenesis. One pout of their wa argment, among other issues, is the increased static stability induced by mid-troposphere 3. warming and surface cooling. Similar fndings are also obtained by Lan and Kim [2007]

is on a seasonal time-scale. Reale et al. [2009b;, hereatter RA09b, relying upon a global 7 Gata assiniation and noleling effort and the production of high quality andyses, also 3. suggest that high dust content is associated with a themal dipole: relatively wam at 36 600-700 hPa and cooler at about $900 \mathrm{hPa}$ or below. RA09b findings are supported by s. the fact that the finite-romme drming of the NASA GEOS 5 is particular suitable to " Maintain fine thermal featmes avoling umealistic dispersions. 


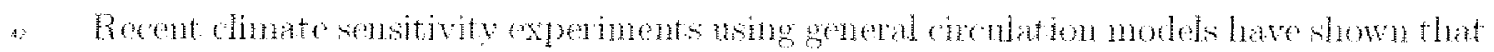

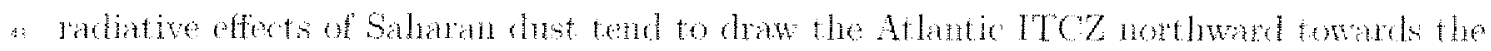

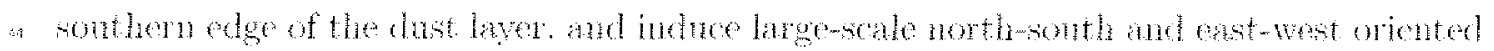

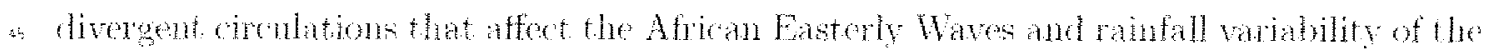
* West African monsoni and clinate of the Atlantic [Lan et al 2009: Kim et al. 2010].

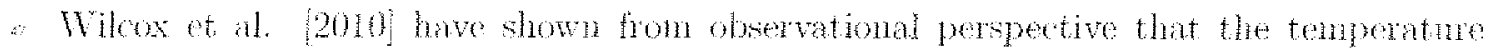

as sucture associated with Saharan air ontbreaks is consistent with prowous work, and that 13 one of the effects of chst ontbreaks is an northwad shift of the Titer Tropical Convergence : Zone (ITCZ). Also within the operational forecasting modeling framework, ovidene has s been provided by Tompkins ef al. 2005 on that an improved representition of arowol (i.e. - seasonally varying instead of fxed leads to a more correct representation of the African 5. Eastery Jet (namely a northward and upward shift, in agreenent with observations).

a In this wotk, the use of interactive aerosol in a global modeling framework provides s resuits fully consistent with Lan et al. [2009], Kim et al. [2010], Wilcox et al. [2010]

and comfrms that the direction stated by the pioncering work by Tomplins et al. [2005] s. needs to be further pursued.

\section{The Model and Data Assimilation System}

4 The global data assimilation and foreasting sytem nsed is the NASA GEOS-5. which a combines the Gudpoint Statistical Interpolation (GSL) andysis algorith developed by a the National Conters for Envoment Predictions (NCEP) (eg. Wu et al. [2002), and 3 nodfed by the NASA Globel Moleling Assmiation Offee (GMAO). with the NASA a atmopheric global forecat model is docmented in Renecker al. 2008. The fore- 


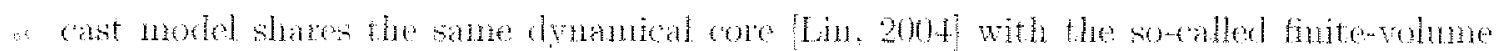

4. General Circulation Model (vGCM), also know as the GEOS-1, but contams a different

* set of plystal parmetizations, pantly developed by die NASA GMAO. The Aerosel

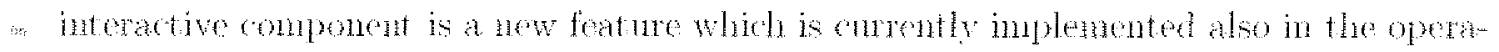

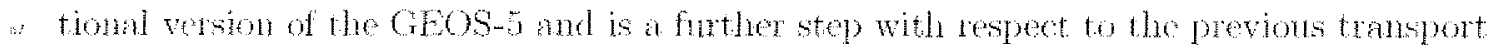

s moded decribed in Colaro et al. 2010 , which merged the Goddart Chemistm, Acrosol.

andation and Trunsport Morel (GOCART) with the GEOS-4. The version described

72 by Colaro et al. 2010 allows the tratment of dist, sea salt, carbonacons and sulfate

n aerosols, producing realistic aerosol disthbutions (validated against ground and satellite-

" based moastrements) which are consistent with the dymanies and the notoonologion

" fieds produced by the GEOS-4. In the version used in this study aerosol transport pro-

in cesses (advection, difusion, convection) are provided by the host GEOS-5 model. with the?

n aerosol specific processes (emission, deposition, simplified sulfate chemistry) as in Colareo

is et al. 2010]. The direct aerosol radiative effect is induded in the GEOS-5, while indirect

" effects on clond/predpitation processes are not included at present.

\section{The Experiments}

Fon sets of 30 b-day forecast experiments at two horizontal resolutions $\left(0.5^{\circ} \times 0.67^{\circ}\right.$

is and $0.25^{\circ} \times 0.33^{\circ}$, both with 72 verteal levels), are performed. They are thitialized

* daily at $60 \mathrm{z}$, starting at 00215 Angust 2000. from the same set of analyses used in

* RAO9b. These were produced by assimilating all conventional and satelite observations

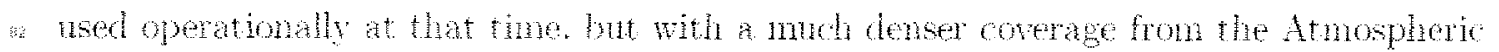

s: Infrated Sonder (AIRS), obrained by ingesting cloudy retrievals instead of clearshy 
$x-6$

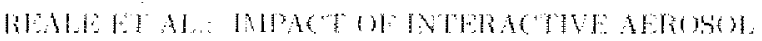

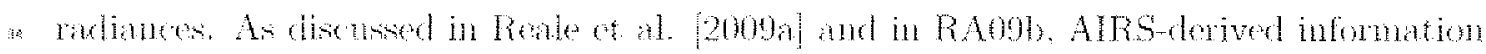

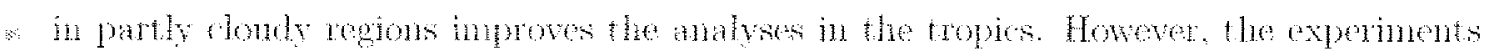

andibed in this aticle ane thataterized by the inchion or exchision of interative

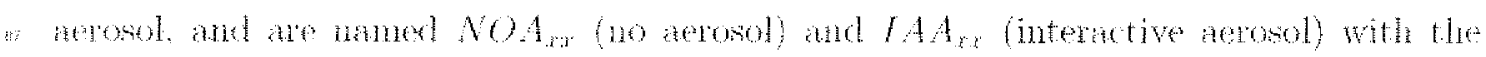
s. sutfix r. indicating the $0.50^{\circ}$ or $0.25^{\circ}$ forectst respectively.

\section{Results}

s As a preliminary metric to asses the impact of interactive acrosol, the anomaly core-

wation for all sets of 305 -day foreasts is comprited aganst operational NCEP analyses.

a: The impact is virtwily zero: the insertion of interactive aerosol does not affect the globally

anerged skill of the system. In FSt the anomaly conelations of $N O A_{50}$ and $J A A_{50}$ are

"compared; the $0.25^{\circ}$ forecasts provide identical resnlts (not shown). The lack of globat

s; impact of the interactive aerosol is understandable becanse the promaction of dast is con-

wh fined to few areas of the world, and does not occur at all times even in the dust-producing

se regions. However, it is important to notice that the forecast still does not degrade as a

ar consequence of the insertion of aerosols. which represents a major change in the model's

s plysics.

3. At the same time it is crucial to emphasize that. for states of the atmospheres associated

whin spentic weather systens, at tines in which dust production is strong, and selected

s. regions are andyzed, the impact of aerosol insertion ts very large and dynamically relevant.

In this work we focus on the impact on the African Easterly let (AE) which fows.

wh w w wedominanty enstenty component, at about $650 \mathrm{hPa}$ and abont $15^{\circ}-20^{\circ} \mathrm{N}$. and

which is party controlled by horizontal temperature gradients orer the Sahehm region.

DRAFT July 16, 2010, 4:41pm DRAFT 


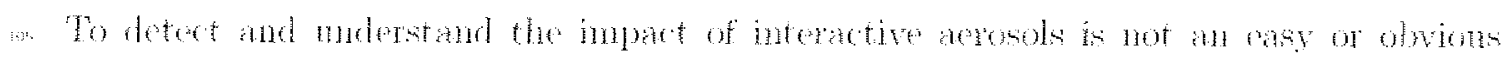

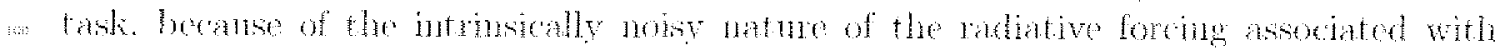

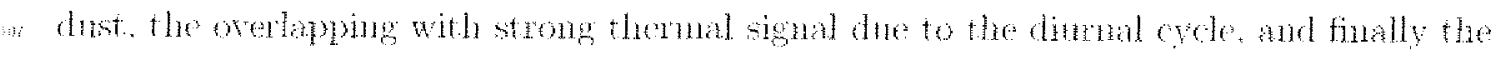

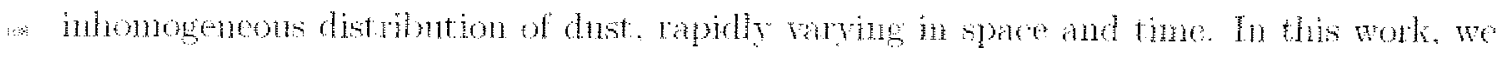

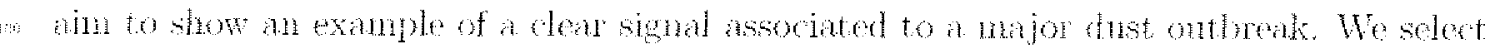

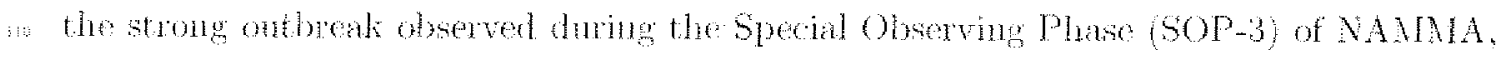
1" moving fon Africa to the Athutic between 25 and 28 Angrat. RAopb suggest that

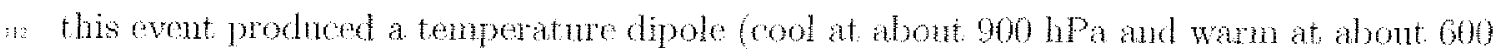

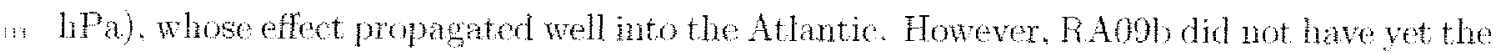

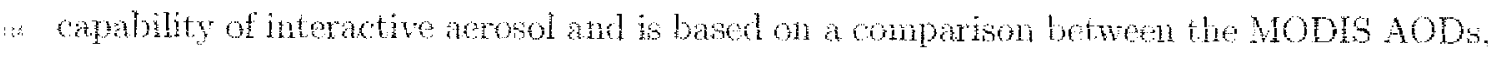
n: and on the tomperatme structure in the CEOS-5 andres and integrations fReale and fian 2010]. In this work we rediscuss the presence of a themal dipole possibly assoctated whth dust, in lieu of this new NASA tool.

As a first step, it is important to verify that the aboverefered dust ontheak is rep anented wel in the simulations. Figure 1 compares the onthreak as represented thongh

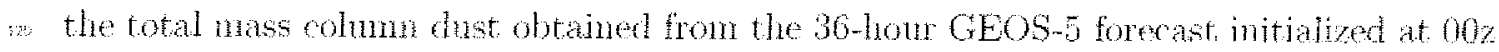
2. Angust, and a composition of AOTs obtaned from MODIS instrments on bond both Aqua and Tema setelites. coresponding to the verification time of $12 z 25$ Angust. The Figne show that the GEOS 5 reprotues a strong dust ontbeak interceting lie African

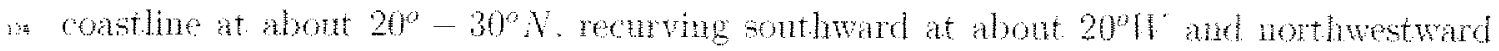
at about $251 \%-35 \%$ 


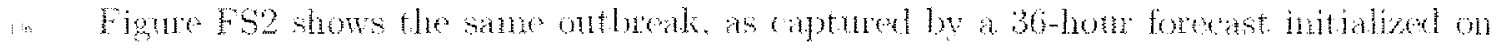
"the following day at 00,25 Augnst 2006 . By companing the obsured AOD from 12226

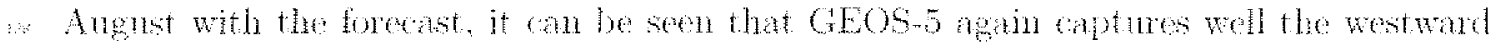

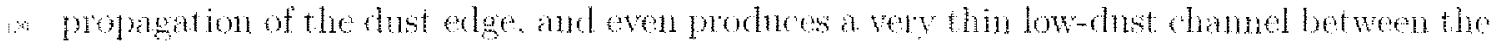

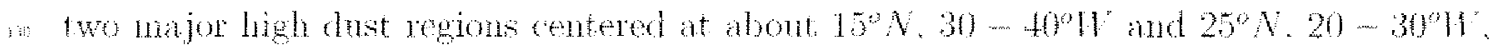

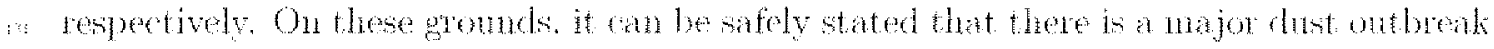
an the GEOS-5, and that its timing and seale correspond well with the MODIS tata.

a The second step is to investignte the impact of this dust ontbreak on the temperature a stmoture, as represented by the GEOS-5. Fignre 2 shows the temperatme impact of

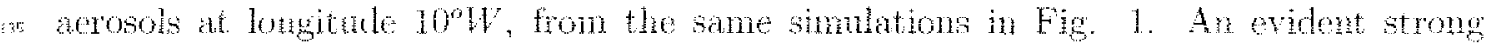
3. thermal dipole. very similar to the one discused in RAO9b and previously by Dunion and : Velden [2004] can be observed: a heating of about $1^{\circ} \mathrm{C}-1.5^{\circ} \mathrm{C}$ between 850 and $500 \mathrm{bPa}$ and a cooling in the lower, near-sutace, levels. A very similar patten in the $I A_{2}$ minus 3: NOA temperatme strutme acros the sane latitude range and at longitude $10^{\circ} \mathrm{W}$ can whe seen also in FS 3, where the corresponding aerosol impact on temperature is computed s: from the 36 hom foremst initialized on the following day (00z 25 Angust) and verifed at $12 \% 26$ Angust. The simulations at $0.50^{\circ}$ provide consistent results (not shown) but with : diluted values and smoother gradents. As discussed in RA09b and Reale and Lan (2010). we the resolution of $0.25^{\circ}$ is better than $0.50^{\circ}$ to investignte the fme structure of the AEJ. :an For this reason. we show only the $/ A_{2} A_{25}$ in the following pictures.

Becanse the AD and the wind over the region are stongly controlled by lower-erel 1a temperature gradients, a change in the themal strueture mot have an inpact on the
DRA F T
July $16,2010,4: 41 \mathrm{pm}$
D R A F T 


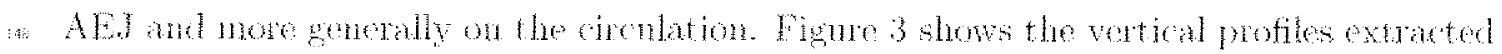

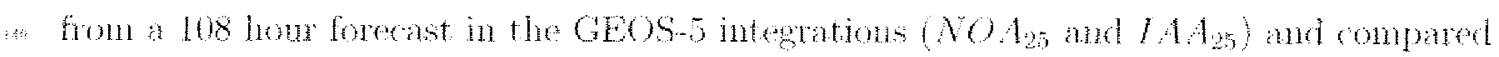
with the profles of remperatme and zomal wint component, obtand from the vertical

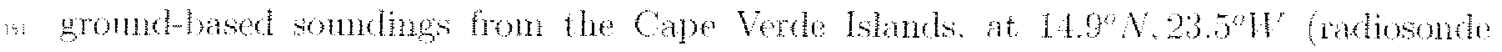

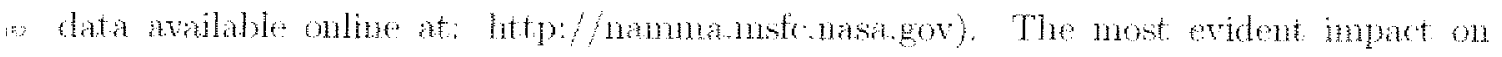

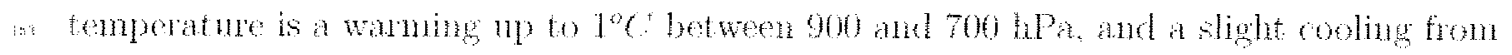
so the near-surface levelis up to $900 \mathrm{hPa}$. The zonal wind pane shows that the verifying andysis and the obserwional profle natch very well, bat the 108 hou NOA2 forecast s. Was a negative bias with respect to the observations, of about $4 \mathrm{~ms}^{-1}$, from the surface to a soohpa. The inpact of the arosol is very evident in the lower levels, reducing the bias of iss about $40 \%$. Whan no dust production is present, the impart on temperatme and zonal wa wind is negligible (not shown). Ako above 600hPa, the impact of the aerosol is virtualiy : zero (not showi).

whe Thative effect of dust is controlled by dirmal ycle and the distribution of aerosol is very noisy; therefore, to obtain a clearer signal on the wind fich and of the AEJ 5a structure, a 5-day average across the forecast initialized on August 25 th is performed.

sh There is an evident northward and wpward shift in the AEJ structure in the zonal wind and temperature fields at $10^{2}$ If (FS 4 ) consequent to this themal anomaly, in agreement sw wh Tomplins et al. [2005), and expected from the themal wind relationship. We w see a simiar thermal anomaty at $10^{\circ} \mathrm{E}$ and a coresponding northward shift in the AE.T

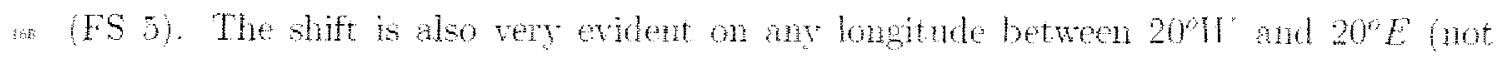
is shom and, to a lesser extent also in the $/ 44_{5}$ experiments (not shown). The sarcity 


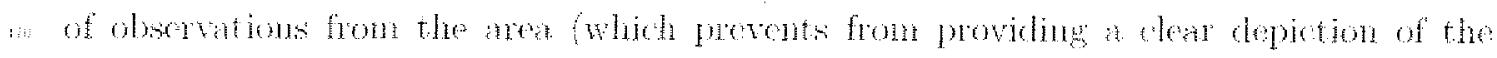

- AEI from olwervations only) dos not allow the valjotion of this northward shift in a

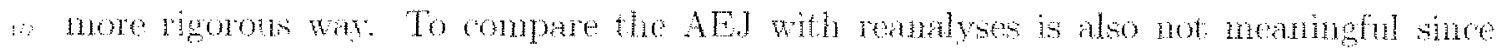

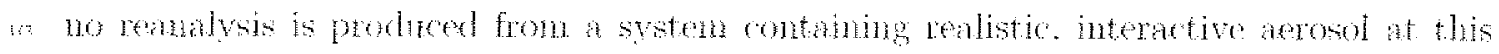

a time. Howner these experiments demonstrate that the effect of mater tive artosol in the

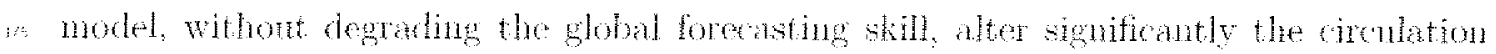
sto over the dustaffected region and provide an improwel vetical profile at one validation point.

\section{Discussion}

July $16,2010,4: 41 \mathrm{pm}$
$D R A F T$ 


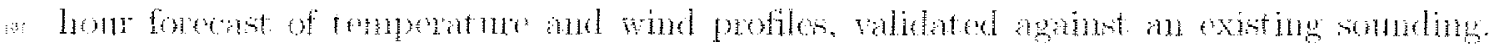

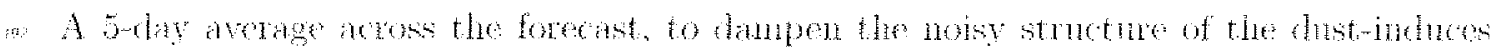

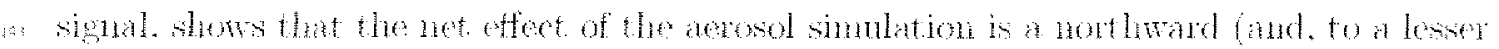

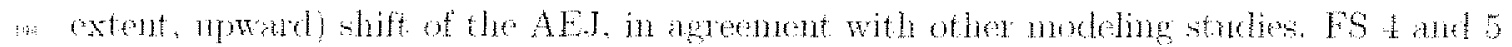

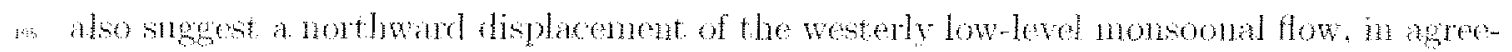

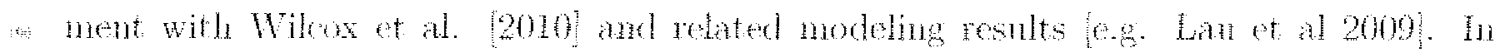
14 this work we have also petomed the same analysis for another dnst ontbreak occured se arond $10-13$ September: wind and temperature anomalies of the sane sign are obtaned, w albeit of a weaker magnitude, being the ontbreak also snbstantialy weaker (not shown).

\section{Conchuing Remarks}

no In this article we show that the nse of interactive acrosol in the GEOS-5 data assimilaw tion and forecasting systen does not impact the global skill but substantially changes the wh themal strut ture over uorthwestem tropical Africa, during an observed dust onbreak, affecting the circulation and particularly the AEJ representation. We valiate the changes xo in temperature and wind with a vertical sonding, showing that the insertion of interactive 20. aerol improves the forecast up to day five for this particular event. However, the lini$\%$ tation of this work is to rely upon modeled aerosol production and distribution. The next

we step. namety teal-tine nse of satellite-terived aresol infomation in global models is a

we tery recent developnent of the most advaned data assimilation systems. In this regard.

w the NASA GMAO is curenty attempting to assmilate rent-time AOTs from MODS.

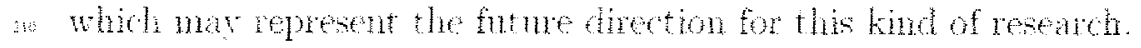


$\mathrm{X}-12$

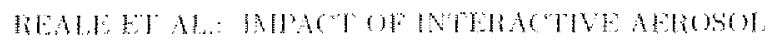

Acknowledgments. The anthom thak Dr. Ramesh Kakar for sinpert through gmat. n. NAMRA and Dr. Tsengdan Lee for allowams on NASA High-End Computing syatomi

\section{References}

n Cartson, T, N. and 1. M. Prospero. (1972). The lazge-scale movement of Saham air

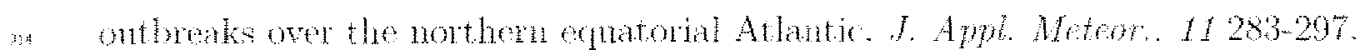

n. Cartson. T. N. and P. Wendling, (1977). Reflected radiane measured by NOAA 3 VHRR

w. is a function of optical deptin for Sahman dust. J Appl. Meteor, 16, 1368-1371.

Carlson T. N., and S. G. Benjamin, (1980), Radiative leating rates for Saharan dust. J.

Atmos Sc. 37. 193213.

n. Colarco, P., A, da Silva, M. Chin, and T. Dien, (2010) Onlme simulations of global aerosol

whe fistributions in the NASA CEOS-4 model and comparison to satellite and gromd based

2 nerosol optical depth. I. Geophys. Res, in press.

an Dunion, , and C. S. Velden. 2004: The mpact of the Saharan Air Layer on Atlantic

w Fropical Cyclone activity. Bull. Am. Meteorol. Soe. 85. 358-365.

Kim, K-M., K. M. Lat, Y. C. Sud. and G. Walker, (2010): Influence of nerosolmadiative

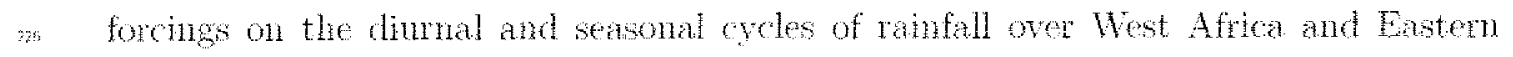

m Atluntic Ocen using GCX simulations. Chm. Dym. doi: 10.1007/s00382-010-0750-1.

2. Lan. K. M.. and K.M. Km. (2007), How uature foled the 2006 huricane foreats. EOS.

Trans. Amer. Geophys Union. 88. 105-17.

wan. K. M. Kim. K. M. Sur. Y. C. Wakes. G. K.. 2009: A GCM stuly of the response of

wo the atmosphere water gele of West Afrom and the Atlantic to Sahan dust radiative forcing. Amm. Grophys 2\% 4023-4037.
$D R A F T$
July $16,2010,4: 41 \mathrm{pm}$
D E. A F T 


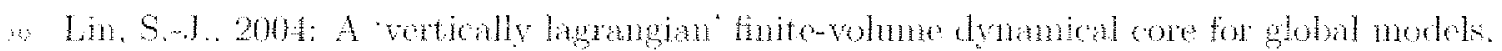

Hon. Wo. Art., 132, 2203-2307.

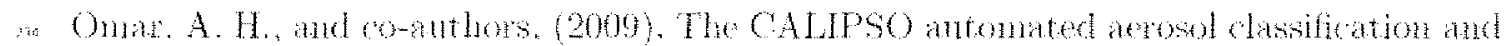

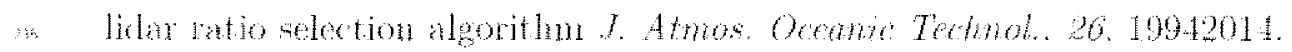

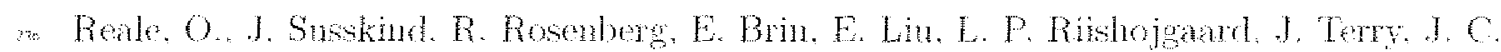

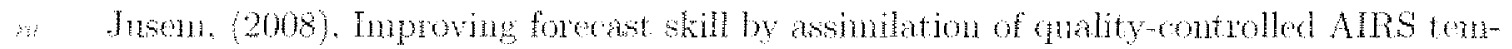

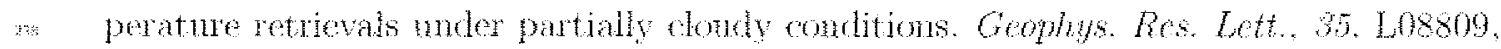

doi:10.1029/2007GLO33002.

at Reale, O. W. K. Lan, .J. Susckind, E. Brin, E. Lin, L. P. Riighojgard, M. Fuentes, R.

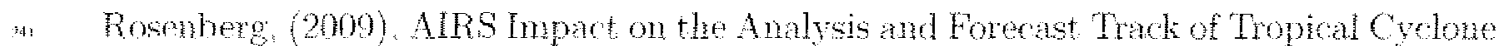

n. Nargis in a global data assimilation and forecasting system. Geophys. Res. Lett. 36,

Lo6812, dot:10.1029/2008GL037122.

Reale, O., W. K. Lan, K. M. Kim, E. Brin, (2009). Atlante tropical crologenete processes

Af during SOP-3 NAMMA in the GEOS-5 glohal data assinilation and forecast system.

J. Atmosph, Sa, 66, 3563-3578.

2a Reale, O. and W. K. Lam, (2010), Reply, J. Amosph. Sci. 67, 24112415.

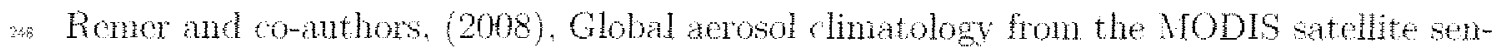

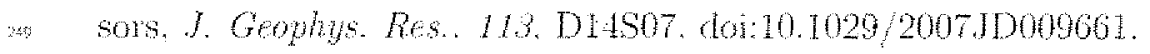

* Reneker. and co-anthors (2008). The GEOS-5 Data Assmilation Syotom. Docn-

m. mentation Versions 5.0.1. 5.1.0 and 5.20 Tedmich Report Series on Gobd Mode

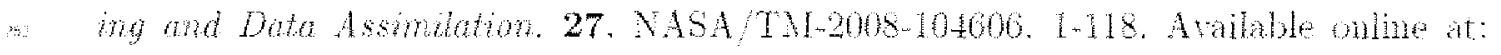

attp:/gmaogscmastgon/pnbs/tm/ 


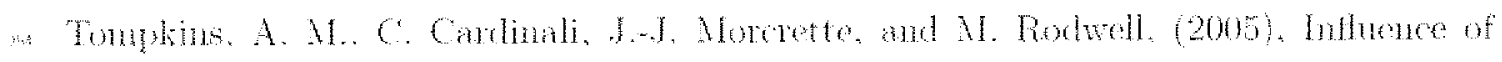

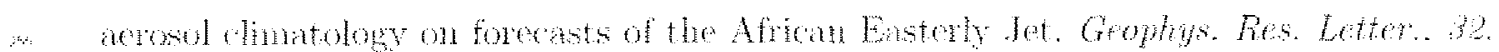

L. L10801. do1:10.1029/2001:LL022180.

a Whos, E. M. K. M. Lan, and K.-M. Kim. (2010) A not hward shift of the north At-

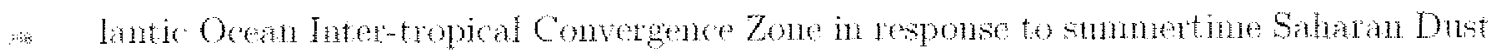

Ontbeaks, Gephys. Res. Lett. 97 doi:101029/2009GLOH77.

a. Wh, W.S. R.J. Pnser and D.F. Parrish, (2002), Threedimensional variational analysis zo: with spatially inhomogeneous covatances, Mon. Wea. Ren, 130, 2905-2916. 


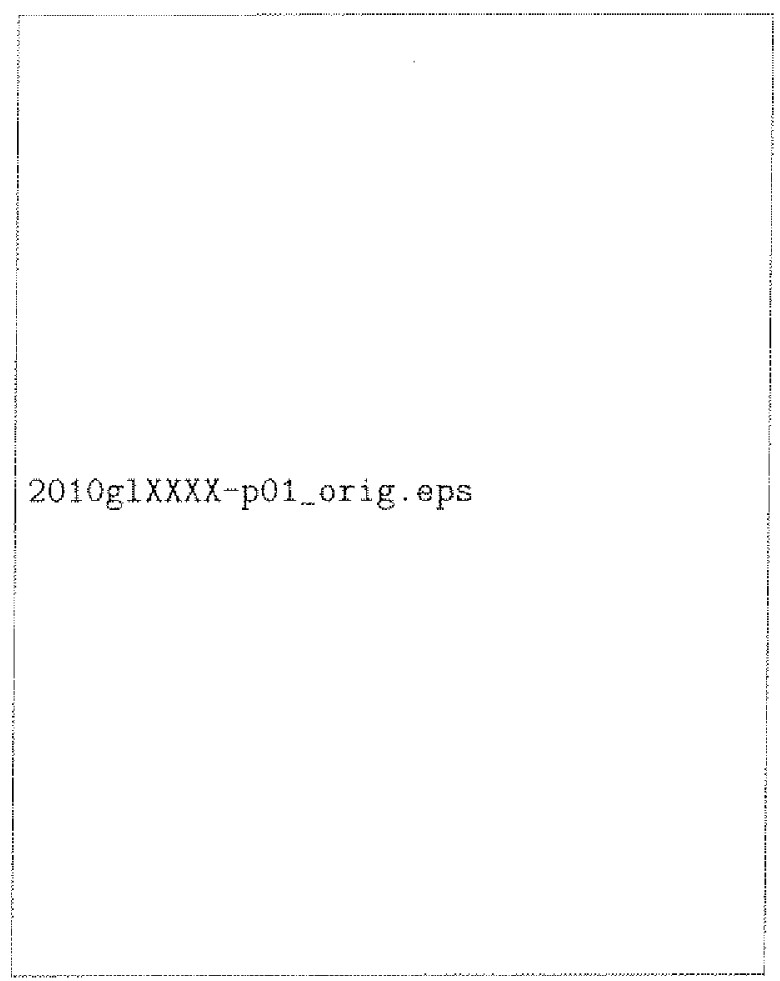

Figure 1. 36-hom forecest (intialized at $00 \mathrm{z} 24$ Ang 2006 ) of total mass colmm aerosol from the GEOS-5, and MODIS ontical depth lot 12225 Ang 2006. 
$x-16$

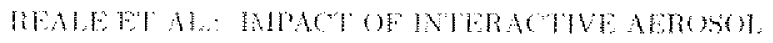

Figure 2. Vertical Meridional coss-section of temperature ( $\%$, at $10^{\circ} \mathrm{W}$ in the GEOS-5

$\mathrm{NOA}_{25}$ simulation for $122,25 \mathrm{Ang} 2006,(36$ hom forecast, witialized at $00 z 24$ Ang). Shaded: IAA25 wim NOA $A_{25}$ difference. 
Figure 3. Vertical profiles of Temperature $\left({ }^{\circ} \mathrm{C}\right.$, left pand) and zonal wind $u\left(\mathrm{~ms}^{-1}\right.$, right panel) at Cape Verde $14.92^{\circ} \mathrm{N}, 23.49^{\circ} \mathrm{W}$ in the GEOS-5 NOA.5 (green) simulation for 12729 Aug 2006, (108 hour forecast, initialized at $00 \mathrm{z} 25$ Ang), verifying analyses (black), compared with observed soundings (parple) at the Cape Verde, from SOP-3 campaign. In the left panel the orange line represents the $I A_{25}$ minus $N O A_{25}$ difference; in the right panel, the actual $I A A_{25}$ u component of the wind. 


\section{GEOS - 5 InOOz24Aug Ver12z25Aug $36 \mathrm{hFc}$}

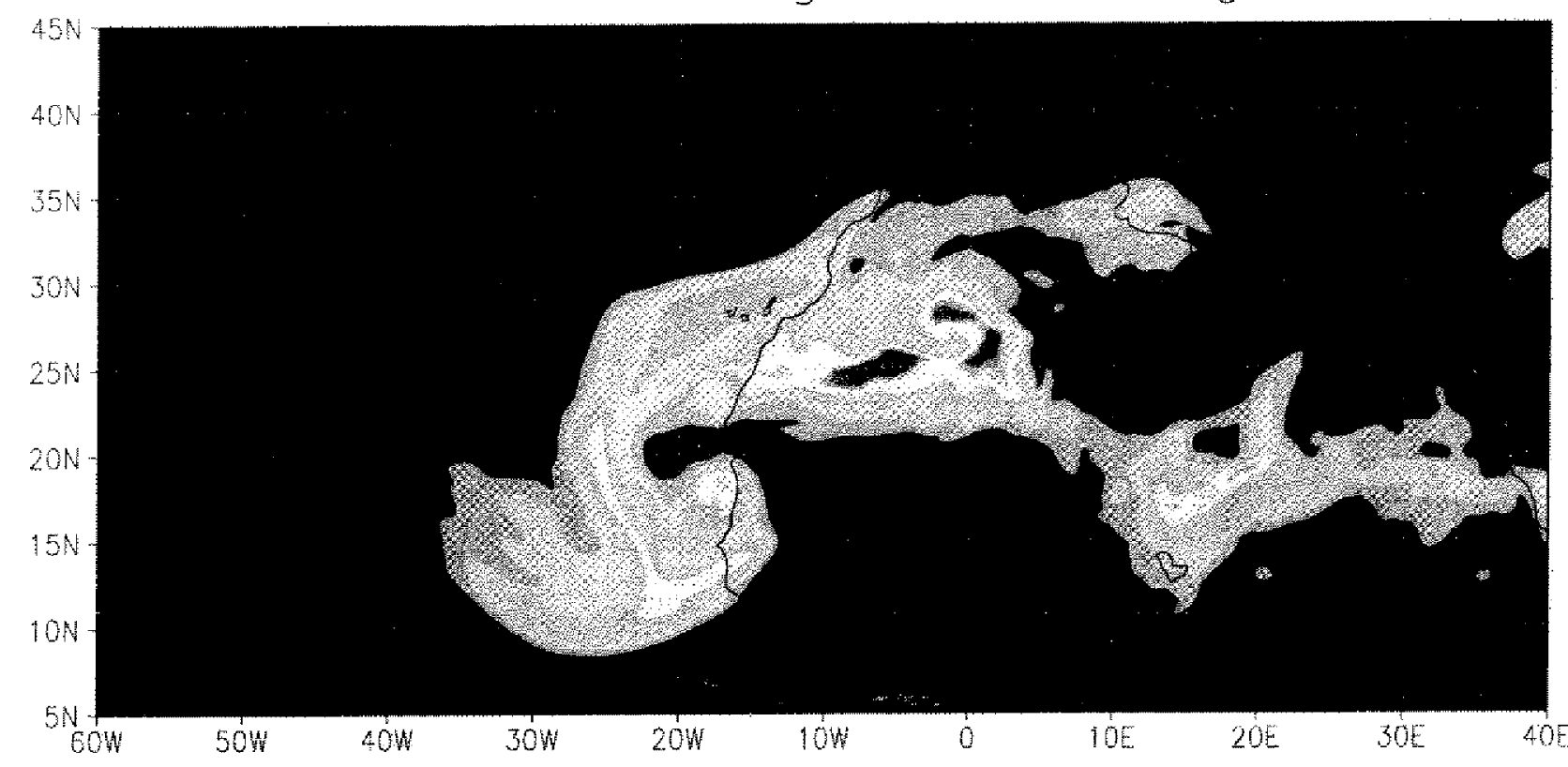

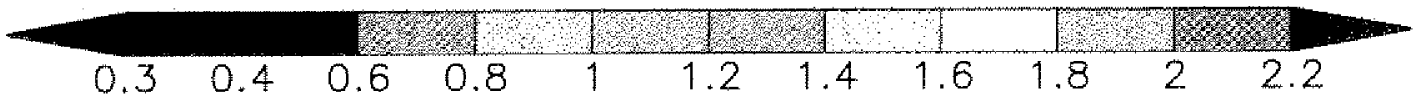

\section{MODIS $12 z$ 25Aug}
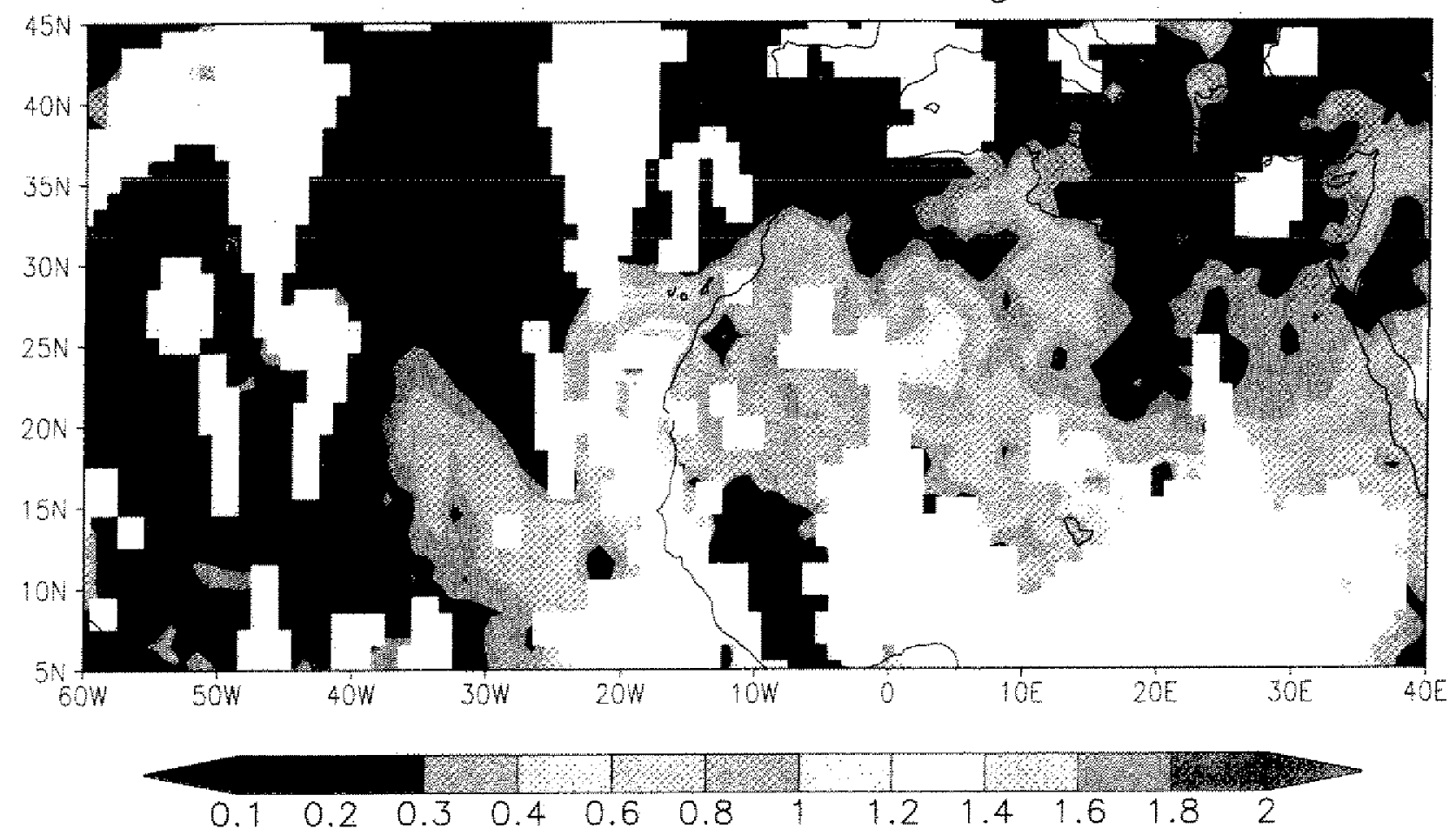


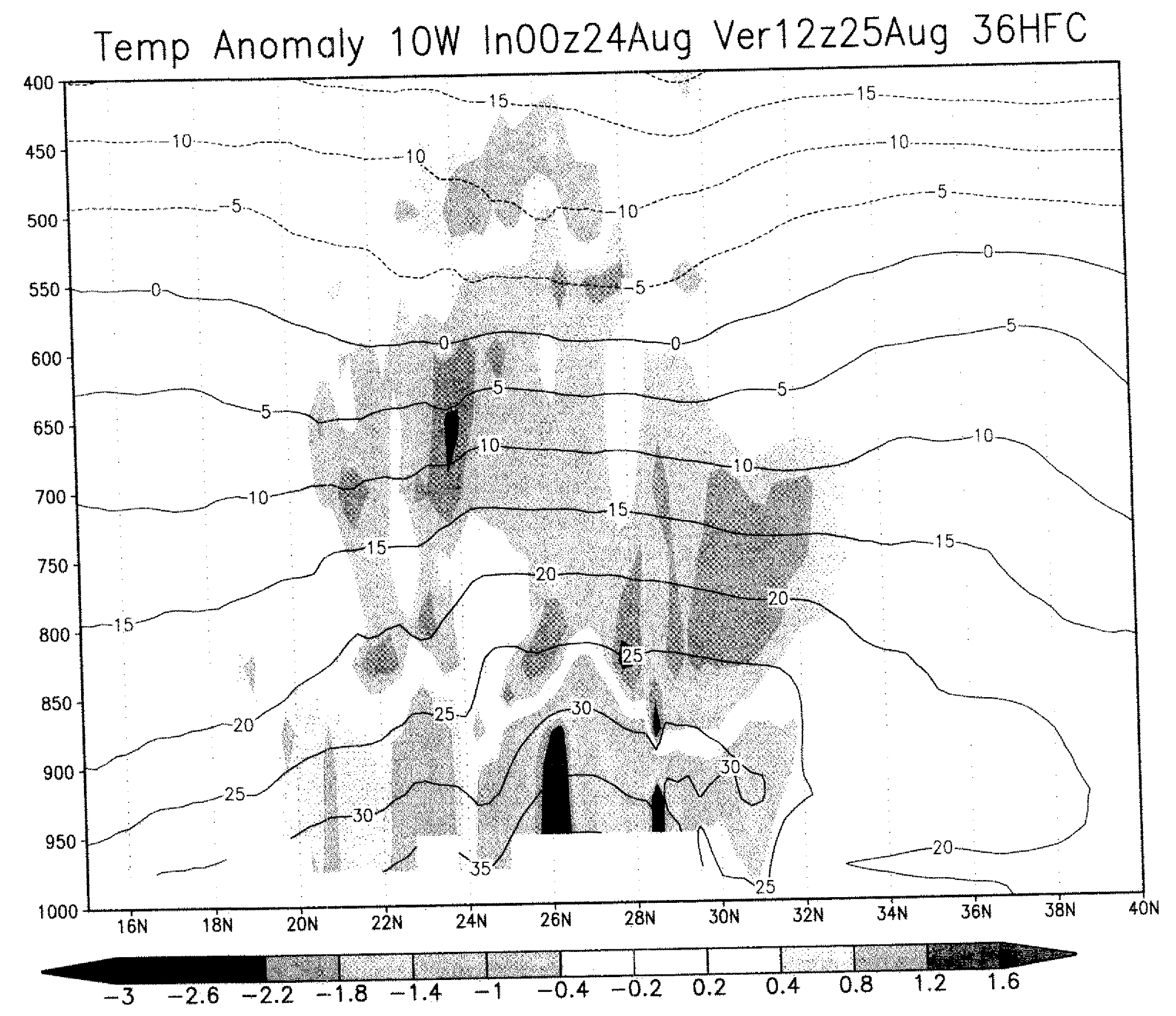



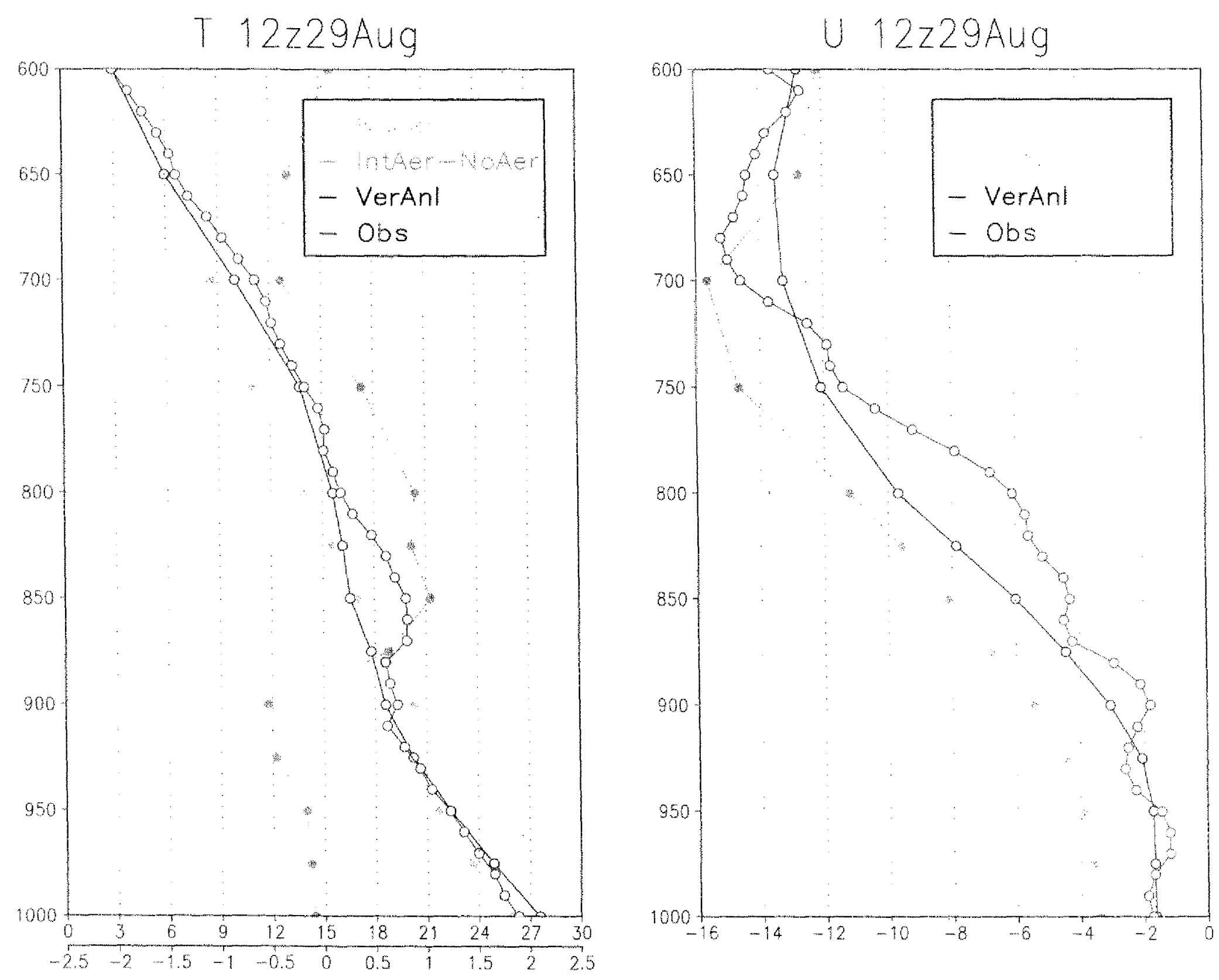